\title{
Avaliação de Crianças Deficientes Visuais através de Jogos Neuropedagógicos
}

\author{
Carla Verônica Marques ${ }^{1}$ \\ Carlo Emmanuel Tolla ${ }^{2}$ \\ Claudia Motta ${ }^{2}$ \\ Samantha $\mathrm{Vrabl}^{2}$ \\ Fábio Lapolli ${ }^{2}$ \\ Lúcio Ângelo ${ }^{2}$ \\ Luciana Daflon ${ }^{2}$
}

\begin{abstract}
Resumo: Este artigo apresenta a metodologia de avaliação neuropsicológica através de jogos aplicados a deficientes visuais, cujo propósito é diagnosticar questões neurocognitivas, neurolinguísticas, de desempenho acadêmico e comportamental da criança. Discutiremos a metacognição do jogo pedagógico virtualizado denominado Cria Conto e suas possibilidades proposicionais em nível audiofonético.
\end{abstract}

Palavras-chave: Psicologia cognitiva. Jogos neuropedagógicos. Neuropedagogia.

\begin{abstract}
This paper presents the neuropsychology evaluation method using games applied to impaired children, in order not only to diagnostic their issues in neurocognition and neurolinguistics but also in their school performance and behavioral matters as well. We shall discuss the metacognition in digital games such as Cria Conto and its possibilities aimed at an audio phonetical level.
\end{abstract}

Keywords: Cognitive psychology. Neuropedagogical games. Neuropedagogy.

\section{Introdução}

O surgimento das tecnologias da informação e comunicação (TICs) aplicadas ao contexto educacional trouxe a lume diversas possibilidades de utilização de ferramentas e disposição de recursos multimídia, tanto para fins de desenvolvimento de estratégias pedagógicas mais eficientes como para a inclusão de crianças com déficits de aprendizagem derivados da dificuldade cognitiva de abstração do conhecimento ou originárias da limitação ou incapacitação de ordem física.

Estatísticas apontam uma taxa de escolarização das crianças de 7 a 14 anos portadoras de defíciência de $88,6 \%$, correspondente a seis pontos percentuais abaixo da taxa de escolarização do total de crianças nesta faixa etária $(94,5 \%)$. Quanto ao grau de instrução, as diferenças educacionais são mais evidentes: $32,9 \%$ da população sem instrução ou com menos de três anos de estudo são portadores de deficiência. As disparidades reduzem-se quanto maior é o nível de instrução, chegando a $10 \%$ de portadores de deficiência entre as pessoas com mais de 11 anos de estudo [1].

\footnotetext{
${ }^{1}$ Instituto Benjamim Constant - Rio de Janeiro - Brasil

\{abrapacarla\} ehotmail.com

${ }^{2}$ Instituto de Matemática - Núcleo de Computação Eletrônica - Universidade Federal do Rio de Janeiro(UFRJ) - Avenida Brigadeiro Trompowski, s/n - Cidade Universitária - 20.001-970 - RJ- Brasil 
Esse panorama indica possibilidades do ambiente virtual como viabilizador da inclusão social, visto que o computador metaforicamente se traduz em extensão libertadora da deficiência na medida em que permite comunicação mediada pelas funções sensório-motoras. Notadamente a internet vem se firmando como um expressivo instrumento mediador-protético, onde a representação mental do ambiente é construída por meio de figuras sonoras imbuídas de significação, produto da interação do deficiente visual com os periféricos de input virtual e a recepção de estímulos sonoros. Muito embora existam barreiras relativas ao acesso econômico, à acessibilidade das páginas eletrônicas, às habilidades no uso de leitores de tela e de digitação em teclados não especificamente ergonômicos para o cego, é evidente o poder que as TICs oferecem a ele. Já existe um pequeno contingente de deficientes visuais que contribui com Wikis, tais como a DVWiki, e que são sensíveis ao modelo preconizado pela Web 2.0 .

A virtualização desse processo comunicativo abrange ainda o acesso a conteúdos não somente limitados a publicações adaptadas ao Braille e evidencia a grande importância do paradigma da usabilidade e da acessibilidade para o desenvolvimento do conteúdo audiofonético e do canal visomotor.

O objetivo deste artigo é apresentar a teoria da elaboração dirigida como instrumento pedagógico de avaliação cognitiva através de jogos, como o Cria Conto, que se encontra em fase de aplicação experimental às crianças que enxergam. Identificamos as possibilidades de extensão aos deficientes visuais, uma vez que todo o processo de virtualização do jogo fundamenta-se no aporte metodológico preconizado pelo psicólogo Franco Lo Presti Seminério e pela professora Carla Verônica Marques, pesquisadora do Instituto Benjamim Constant e psicóloga especializada em Educação Especial há mais de vinte anos.

Apresentaremos na seção 2 a base proposicional do jogo Cria Conto, os aspectos teóricos relevantes à questão da linguagem-código e suas implicações pedagógicas; na seção 4 será detalhado o Cria Conto em sua versão digitalizada, seguindo com as mudanças tecnológicas necessárias no jogo para atender aos deficientes visuais. Concluímos discutindo a metodologia científica suportada na fase de aplicação deste estudo e o modelo de avaliação diagnóstica já configurado para validação.

\section{Base proposicional do Cria Conto}

O Cria Conto é um jogo que objetiva traçar um perfil do imaginário de crianças, de maneira a melhor articular estratégias para estimular seu desenvolvimento cognitivo. Sua proposta é instigar a criança a contar uma história a partir de um cenário, com personagens e outros elementos manipuláveis, como pode ser visto a seguir:

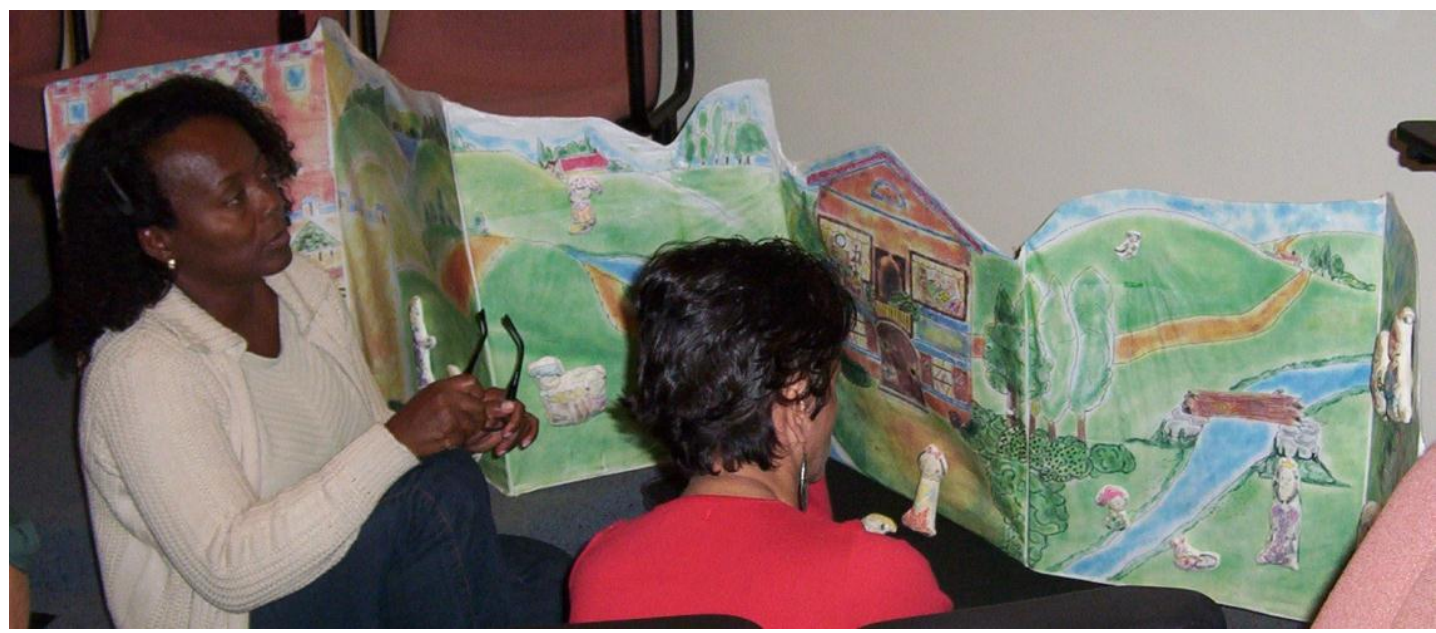

Figura 1. Aplicação do jogo Cria Conto aos professores

Durante as sessões a criança pode percorrer até sete fases, norteadas pelo método denominado Fio Condutor, onde o mediador (um psicólogo ou educador especializado) avalia e reabilita cognitivamente a criança por meio do uso de jogos. O Cria Conto está inserido em um conjunto de jogos metacognitivos produzidos por 
Carla Verônica Marques e que são aplicados segundo o Fio Condutor, também criado pela psicóloga. O ponto de parada no processo de aplicação dependerá dos crivos ou aspectos indicadores que a criança foi capaz de apreender e da reflexão sobre a regra que é viabilizada no jogo. Assim, o Fio Condutor corresponde a uma proposta prática de ordenamento da aplicação da elaboração dirigida, técnica desenvolvida por Seminério e que corresponde à versão 4 do Fio Condutor, conforme apresentado da Figura 2.

A elaboração dirigida é uma modelação experimental que visa provocar a descoberta do metaprocesso por meio da atividade discursiva e reflexiva estimulada na criança, a qual precisará captar o modelo lógico que está sendo trabalhado no jogo, que, por sua vez, possui características cognitivas previamente mapeadas. Todos os jogos neuropedagógicos produzidos por Carla Verônica Marques seguem um protocolo de classificação denominado "Nave-Mãe" (Figura 3), onde cada jogo é selecionado segundo os aspectos neurolinguísticos que devem ser desenvolvidos na criança, ou seja, quais funções cognitivas, linguagens-código, canais linguísticos, processos-tarefa, nível semiótico e elementos estarão sendo trabalhados com o jogo para que ela atinja o patamar cognitivo desejado. Antes da aplicação do Fio Condutor é realizada uma avaliação do histórico clínico da criança (pediátrico, oftalmológico e audiométrico, neurológico) e de seu desempenho acadêmico, que auxiliam na identificação do tipo de jogo mais adequado a ela.

\begin{tabular}{|c|c|c|c|c|c|c|}
\hline VERSÃO 1 & VERSÃO 2 & VERSÃO 3 & VERSÃO 4 & VERSÃO 5 & VERSÃO 6 & VERSÃO 7 \\
\hline $\begin{array}{l}\text { AVALIAÇÃo } \\
\text { ESTÁTICA }\end{array}$ & $\begin{array}{l}\text { AVALIAÇÃo } \\
\text { DINÂMICA }\end{array}$ & $\begin{array}{c}\text { AVALIAÇÃO } \\
\text { DINÂMICA }\end{array}$ & $\begin{array}{l}\text { AVALIAÇÃo } \\
\text { DINÂMICA }\end{array}$ & $\begin{array}{c}\text { AVALIAÇÃo } \\
\text { ESTÁTICA }\end{array}$ & INTERVENÇÃO & $\begin{array}{c}\text { REPETIÇÃO } \\
\text { DAS } \\
\text { VERSÔES }\end{array}$ \\
\hline $\begin{array}{c}\text { APRESENTAÇÃO } \\
\text { DO ESTIMMULO }\end{array}$ & $\begin{array}{c}\text { MEDIAÇÃo } \\
\text { PARAA } \\
\text { CONSTRUČ̃̃o } \\
\text { DA REGRA }\end{array}$ & $\begin{array}{c}\text { CONSTRUÇÃO } \\
\text { DA REGRAACOM } \\
\text { OBJETOS } \\
\text { MANIPULÁVEIS }\end{array}$ & $\begin{array}{l}\text { ELABORAÇÃo } \\
\text { DIRIGDA }\end{array}$ & $\begin{array}{l}\text { RETESTE } \\
\text { MEDIADO }\end{array}$ & & $\begin{array}{c}1 \mathbf{E} 2 \\
\text { COM } \\
\text { TAREFAS } \\
\text { DIFERENTES }\end{array}$ \\
\hline
\end{tabular}

Figura 2. O método Fio Condutor

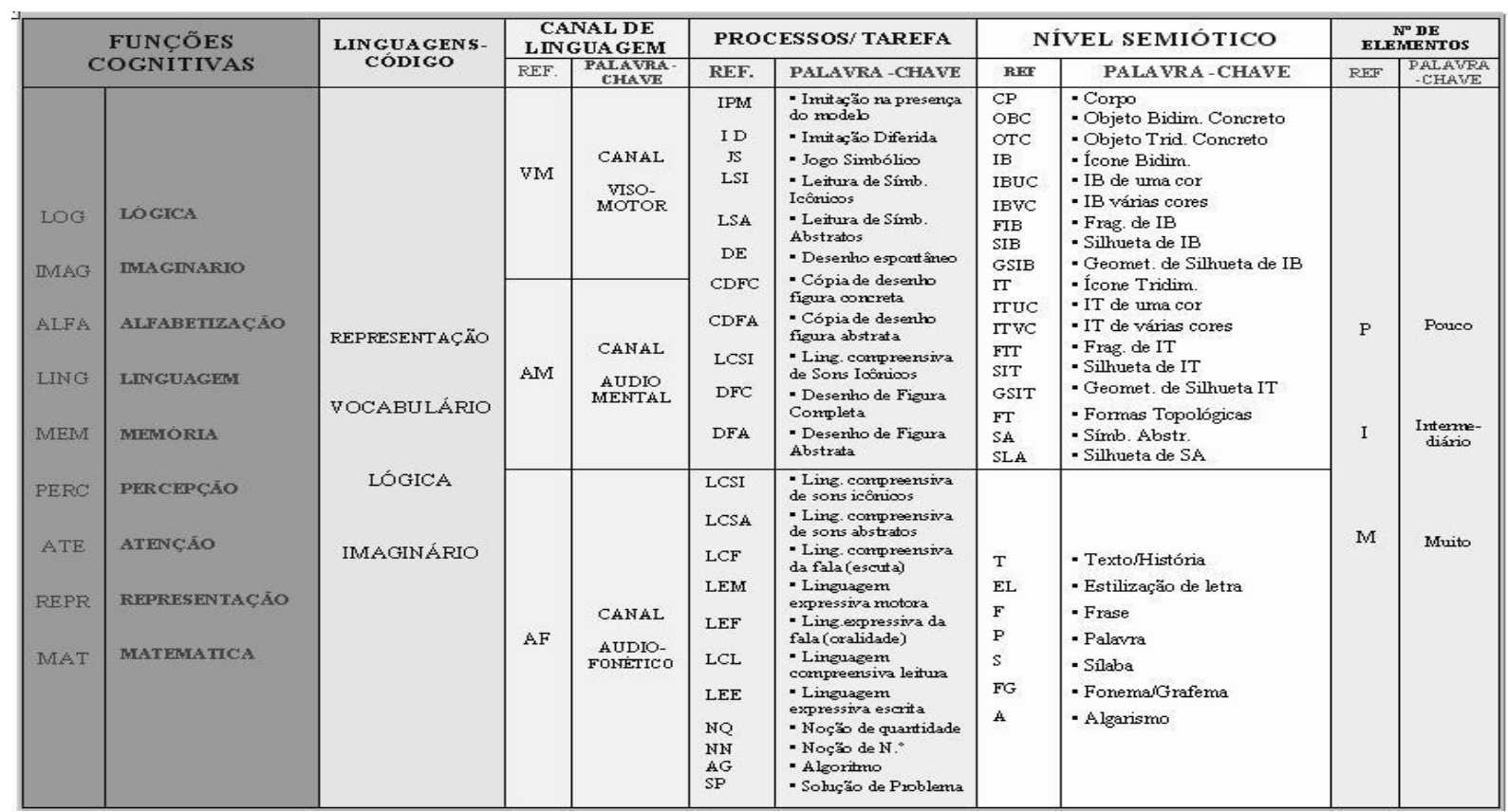

Figura 3. Protocolo de classificações de jogos neuropedagógicos

Simultaneamente às informações coletadas pelo aplicador (psicólogo ou um professor especializado) durante a sessão de jogo, toda a narrativa oral da criança é registrada e, com base nesta, são realizadas avaliações 
a fim de estabelecer critérios que denotem projeções da criança a determinadas características, a partir das quais poderá ser inferida a sua assinatura cognitiva. De acordo com os objetivos sociais e educacionais, espera-se que esta proposição metodológica ofereça subsídios para o desenvolvimento de materiais didáticos diversos por colaboração interdisciplinar, um passo significativo para a implementação na rede escolar fundamental e de atividades paralelas às da programação educacional, com fins de desenvolvimento da cognição e da linguagem. Assim, a criança terá condições de sistematizar seu pensamento de forma mais elaborada e mais consciente, uma vez que conseguirá extrair as regras de todo e qualquer conteúdo, educacional ou não. A proposta do método do Fio do Condutor, a qual seu próprio nome denota, é oferecer um caminho que conduza a criança a refletir sobre suas ações, seus pensamentos e as informações que diariamente processa, levando-a a pensar de maneira diferente e a construir, em última análise, seu modo de pertencer no mundo [2].

Tendo em vista o profundo arcabouço teórico que reveste este trabalho de avaliação neuropedagógica, existem conceitos importantes que devem ser esclarecidos, tais como a definição de imaginário. Segundo Seminério et al. [3], o ato de pensar é um ato imaginário independente de prévio conhecimento da realidade. $\mathrm{O}$ imaginário vai além do conceito de dublagem do real ou de imaginação, isto é, o que se apresenta como real corresponde a um modo de organização e construção que se opera primeiramente como atividade imaginária. A compreensão deste modo de organização mental foi amplamente pesquisada por Seminério durante mais de vinte anos, com o objetivo de identificar novas possibilidades de aceleração cognitiva para fins de aprendizagem. Vivemos não preponderantemente num espaço físico, mas em âmbito do imaginário, que antecipa cada ato material e o prolonga num espaço social, onde o discurso ocorre até quando nos encontramos sozinhos - o simples ato de ler, escrever ou de pensar dificilmente destrói o "cenário imaginário" dos personagens nos que rodeiam, escutam, observam e conduzem a uma reflexão.

Outro ponto importante é a premissa de que a espécie humana possui uma capacidade inata, de cunho reflexivo e recursivo, com o poder de dublar e captar invariâncias através da ação ou pela representação oferecida pelo outro, como um modelo pronto para ser refletido [4]. Apresenta-se na Figura 4 um exemplo de aplicação do jogo Cria Conto, segundo o método Fio Condutor, já antecipando aspectos do jogo no ambiente virtual. O mediador pergunta à criança, que age e interpreta a história de acordo com cada versão, com base nos registros digitalizados do jogo, e produz, ao final, o perfil neuropsicológico do imaginário da criança.

\section{Versão Mediador Criança Jogo Virtualizado}

\begin{tabular}{|c|c|c|c|}
\hline 1 & $\begin{array}{l}\text { 1. Disponibiliza o jogo } \\
\text { no computador. } \\
\text { 2. Por favor mexa e } \\
\text { me conte o que você } \\
\text { está vendo. }\end{array}$ & $\begin{array}{l}\text { Na tela, a criança vê o } \\
\text { jogo e pode interagir } \\
\text { somente com a tela. A } \\
\text { criança somente age, } \\
\text { não interpreta. }\end{array}$ & $\begin{array}{l}\text { O jogo completo (enxoval 1). Os } \\
\text { personagens e o cenário não } \\
\text { podem ser movidos, o jogo é } \\
\text { totalmente estático. } \\
\text { A única diferença para uma foto } \\
\text { estática é que os personagens } \\
\text { recebem um efeito de } \\
\text { luminosidade quando o ponteiro do } \\
\text { mouse passa por cima deles. }\end{array}$ \\
\hline 2 & $\begin{array}{l}\text { 3. Por favor, conte o } \\
\text { que você fez. }\end{array}$ & $\begin{array}{l}\text { A criança conta o que } \\
\text { está vendo (somente } \\
\text { interpreta, não mexe no } \\
\text { jogo). }\end{array}$ & $\begin{array}{l}\text { Jogo indica o que a criança fez, } \\
\text { pois armazena e mostra ao } \\
\text { mediador os movimentos gerados } \\
\text { pela criança na tela. }\end{array}$ \\
\hline $\mathbf{3 A}$ & $\begin{array}{l}\text { 4. Por favor desmonte } \\
\text { o jogo e monte de } \\
\text { outro jeito. }\end{array}$ & $\begin{array}{l}\text { A criança pode fazer o } \\
\text { que quiser: pode alterar } \\
\text { o design metacognitivo, } \\
\text { encaixar as peças de } \\
\text { outra maneira. } \\
\text { A proposta é a criança } \\
\text { ter a liberdade } \\
\text { de manipular o jogo } \\
\text { para construir novas } \\
\text { regras (estórias). A } \\
\text { criança age e interpreta }\end{array}$ & $\begin{array}{l}\text { Todas as peças do jogo são } \\
\text { manipuláveis. Na tela precisarão } \\
\text { ser exibidas todas as peças } \\
\text { desmontadas e separadas. A } \\
\text { criança terá a liberdade de arrastar } \\
\text { para onde quiser, e que a tela } \\
\text { deve preservar essa ordenação da } \\
\text { criança. Gravar o que a criança } \\
\text { fala. }\end{array}$ \\
\hline
\end{tabular}




\begin{tabular}{|c|c|c|c|}
\hline 3B & $\begin{array}{l}\text { 5. Conte para mim o } \\
\text { que fez de novo. O } \\
\text { que foi difícil e o que } \\
\text { foi fácil? }\end{array}$ & $\begin{array}{l}\text { A partir da nova } \\
\text { ordenação feita com } \\
\text { as peças do jogo, conta } \\
\text { a nova estória, ou seja, } \\
\text { a relação entre as } \\
\text { peças. }\end{array}$ & $\begin{array}{l}\text { A tela mantém o mesmo } \\
\text { comportamento da Versão } 3 \mathrm{~A} \text { e do } \\
\text { mesmo jeito que a criança ordenou, } \\
\text { para que assim possa recontar a } \\
\text { sua história. }\end{array}$ \\
\hline 4 & $\begin{array}{l}\text { 6. Perguntas da } \\
\text { elaboração dirigida } \\
\text { 7. Observa a produção } \\
\text { da criança na versão } 3 \\
\text { em relação ao crivo do } \\
\text { jogo (início da } \\
\text { intervenção) }\end{array}$ & $\begin{array}{l}\text { A criança precisa falar } \\
\text { e responder às } \\
\text { perguntas. A criança } \\
\text { não joga. } \\
\text { Somente sofre } \\
\text { mediação verbal. }\end{array}$ & $\begin{array}{l}\text { A tela permanece com os } \\
\text { personagens e, principalmente, com } \\
\text { o cenário manipulável. A } \\
\text { mudança nesta fase do jogo é } \\
\text { pequena, dando ênfase maior à } \\
\text { aplicação da elaboração dirigida. } \\
\text { A gravação é disponibilizada para } \\
\text { o mediador. Este é um item ainda a } \\
\text { ser implementado. }\end{array}$ \\
\hline 5 & $\begin{array}{l}\text { 8. Apresenta outras } \\
\text { peças, outras cores } \\
\text { (enxoval 2) } \\
\text { 9. Pergunte o que você } \\
\text { está vendo? }\end{array}$ & $\begin{array}{l}\text { Na tela a criança vê o } \\
\text { jogo e pede para } \\
\text { interagir somente com } \\
\text { a tela. Os } \\
\text { personagens ainda } \\
\text { estão fixos. }\end{array}$ & $\begin{array}{l}\text { Esta fase não foi implementada no } \\
\text { jogo virtualizado. A ideia é que o } \\
\text { mesmo jogo completo (com todas } \\
\text { as peças manipuláveis) seja } \\
\text { disponibilizado, porém com novos } \\
\text { personagens (enxoval } 2 \text { ). }\end{array}$ \\
\hline
\end{tabular}

\section{Linguagem-código e suas implicações pedagógicas}

Seminério [5] utiliza a noção de linguagem como uma forma de representar simbolicamente informação, pois o próprio pensamento e a cognição são vistos por ele como uma linguagem. Dessa forma, ele teoriza que a linguagem da cognição é subdividida em quatro linguagens, que obedecem a uma hierarquia de associações de estímulos sensório-motores que captamos do ambiente e que representamos mentalmente por meio de tais estímulos. Assim, o conhecimento deriva de um sistema de códigos com significados e significantes interconectados, onde a composição das representações gráficas é formada pela associação de estímulos visuais com a representação mental de imagens e a linguagem audiofonética é produzida pela associação de estímulos sonoros com a representação mental constituída por meio de figuras sonoras. Tais reconstruções mentais da representação do mundo físico demandam estratégias pedagógicas que privilegiem os canais de linguagem como caminho da construção do conhecimento.

A principal estratégia de melhoria da capacidade de aprendizagem é oferecer ao aluno estruturas de linguagem mais acessíveis ao seu nível cognitivo. Essas estruturas devem ser capazes de proporcionar, a partir do nível mais alto de linguagem em que está codificado o aprendizado, a desconstrução dos signos-significantes estabelecidos em linguagens anteriores. Isso ocorre até que se encontre um nível de invariância ao qual ele possa estabelecer uma correlação de significados, seja entre o nível e estrutura de linguagem identificada com sua capacidade cognitiva, seja entre o nível e estrutura de linguagem de nível mais alto em que se encontra codificado o conhecimento.

Pela estruturação da linguagem-código proposta por Seminério podemos observar que a organização e captura do conhecimento se dão pelo encapsulamento do conteúdo através da forma, onde signos-significantes são construídos a cada nível de linguagem (L1, L2, L3 e L4), formando invariâncias capazes de serem identificadas, controladas e reaplicadas em forma de regras. A linguagem e, principalmente, a metacognição se estruturam em quatro níveis:

- L1 - Linguagem mais elementar e arcaica do processo cognitivo, que utiliza os inputs psicofisiológicos da visão e cinestesia geral, bem como da audição e cinestesia da fonação, como signos-significantes para organizar em conjuntos combinatórios seus contextos significativos. Trata-se da capacidade inata da percepção;

- $\quad$ L2 - Linguagem que utiliza os inputs das estruturas figurais decorrentes da linguagem anterior como signos-significantes para organizar em conjuntos combinatórios seus contextos mais 
significativos. Representa a possibilidade associativa de se acoplar a uma estrutura figural presente um sentido experimental, ou seja, associar formas L1 a modos virtuais de ação elementar, bem como às formas de atribuição de significado empírico. Trata-se da capacidade de criar significados a partir da percepção;

- L3 - Linguagem que utiliza os inputs das figuras estruturais decorrentes da linguagem anterior como signos-significantes aptos a formar com eles contextos significativos organizados com sentido episódico: em termos imaginíficos no canal visomotor, em termos de frases discursivas no canal audiofonético. Trata-se da capacidade de criar sentido a partir de significados e, assim, construir o raciocínio;

- L4 - Linguagem que utiliza os inputs decorrentes de todas as linguagens anteriores, notadamente a partir da L3 como signos-significantes, aptos a formar invariâncias captadas como regras controláveis e reversivelmente reaplicáveis às suas fontes. Constitui em si a atividade metaprocessual que permite desenvolver controle consciente sobre qualquer processo cognitivo, incluindo a reflexividade da regra por ele gerada, tornando-se, assim, fonte para estruturação de qualquer tipo de lógica. Trata-se da capacidade de controlar de forma consciente significados, sentidos e raciocínio constituindo a lógica.

Através desses níveis de linguagem a técnica de elaboração dirigida criada por Seminério atua em tais níveis de linguagem, uma vez que fornece um modelo lógico a ser elaborado pelo aluno, permitindo-lhe que modele cognitivamente através da imitação provocada. Nesse processo o aluno é levado a compreender a existência de regras, sem que elas em nenhum momento sejam claramente explicitadas pelo professor-aplicadormediador: são percebidas pelo aluno como derivativas de um conjunto de invariantes decodificados em estruturas de linguagem que fornecem uma via de acesso aos diferentes mecanismos cognitivos com os quais ele é dotado, constituindo, assim, a capacidade de elaborar uma explicação para realidade percebida e transformada.

Essa perspectiva hierarquizada no processo cognitivo se traduz, a cada salto de linguagem, na redução fenomenológica de sentido. Quando estruturamos o conhecimento, reduzimos o que é captado do ambiente pelos sentidos em informação, que, em seguida, transformamos em significação, que, por sua vez, compomos hierarquicamente as mensagens construídas ao longo das linguagens superpostas. Assim, toda a realidade passa a ter uma existência puramente fenomenal no sentido informacional. Esse reducionismo só é percebido quando há uma variação que nos faz retroagir cognitivamente um ou mais níveis de linguagem (L1, L2, L3 e L4), em busca de invariantes prefixados em todas as linguagens anteriores, capazes de conectar o novo conhecimento emergente com os significados anteriormente estabelecidos e fundamentados, possibilitando uma reversibilidade reflexiva para a identificação e construção de uma regra, caracterizando o aprendizado. Nesse contexto o jogo é fundamental para que os processos de desenvolvimento cognitivo se consolidem, resultando em saltos cognitivos de aprendizagem, já que a criança acessa linguagens e modelos anteriormente assimilados para construir a regra [6].

\section{A implantação digital}

A decisão de virtualizar o jogo Cria Conto é sustentada pelas seguintes premissas [7]:

- possibilidades de registro e armazenamento automático das informações que servem de insumos para projeção heurística de padrões cognitivos, onde os crivos (indicadores cognitivos) são matematizados;

- capacidade de reutilização através de plataforma modelo, auxiliando na produção de novos jogos e em possibilidade de extensão a deficientes visuais, motoras e auditivas;

- as características gráficas e o design metacognitivo do jogo são preservados, bem como a mediação;

- disseminar o processo de avaliação neuropsicológica às regiões carentes de profissionais especializados em educação especial e neuropedagogia e de alunos que não têm condições econômicas para atendimento; 
- as perdas decorrentes da virtualização do jogo relativas à manipulação física dos elementos pela criança serão minimizadas por meio de canções de fundo, animações e respostas sonoras dos personagens.

O Jogo Cria Conto na versão virtual é composto de duas interfaces: a tela da Criança e a tela do Aplicador, que interagem entre si: a primeira corresponde ao local do jogo, com os cenários e personagens para a criança desenvolver sua história; a segunda apresenta o ambiente com recursos para acompanhamento do jogo.

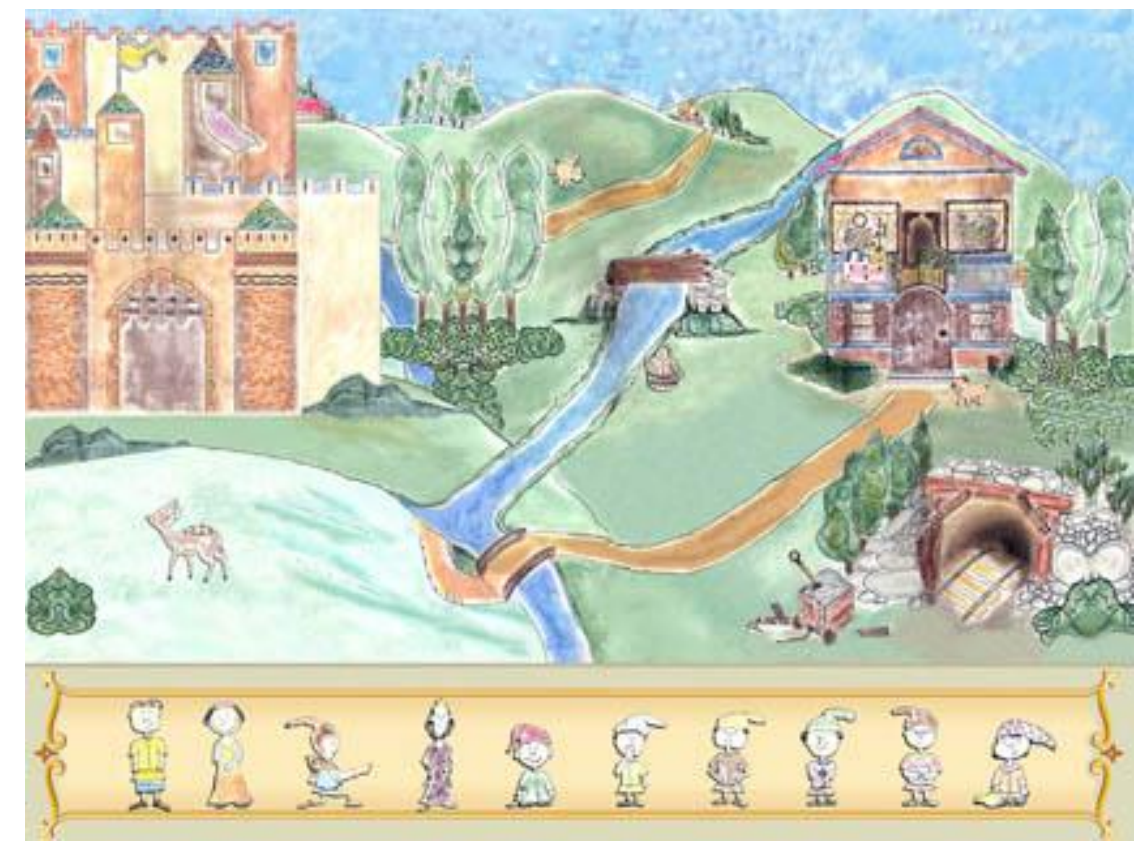

Figura 5. Interface da criança no jogo virtualizado

Durante a sessão de jogo não há respostas certas, erradas ou mensagens automáticas, nem é requerido conhecimento prévio da criança em informática. Ela poderá arrastar os personagens e contar a história enquanto as fases do Fio Condutor são aplicadas.

No decorrer do jogo, as ações da criança são automaticamente registradas e podem ser consultadas na tela do aplicador, tais como: desistência do jogo, colocação do personagem no cenário, colisão entre personagens e elementos do cenário; mudanças de cenário; devolução de personagem; movimentação do mouse e tempos das jogadas. O aplicador pode, ainda, registrar suas próprias observações para a sessão de jogo, as quais são armazenadas em bases de dados para referências futuras. 


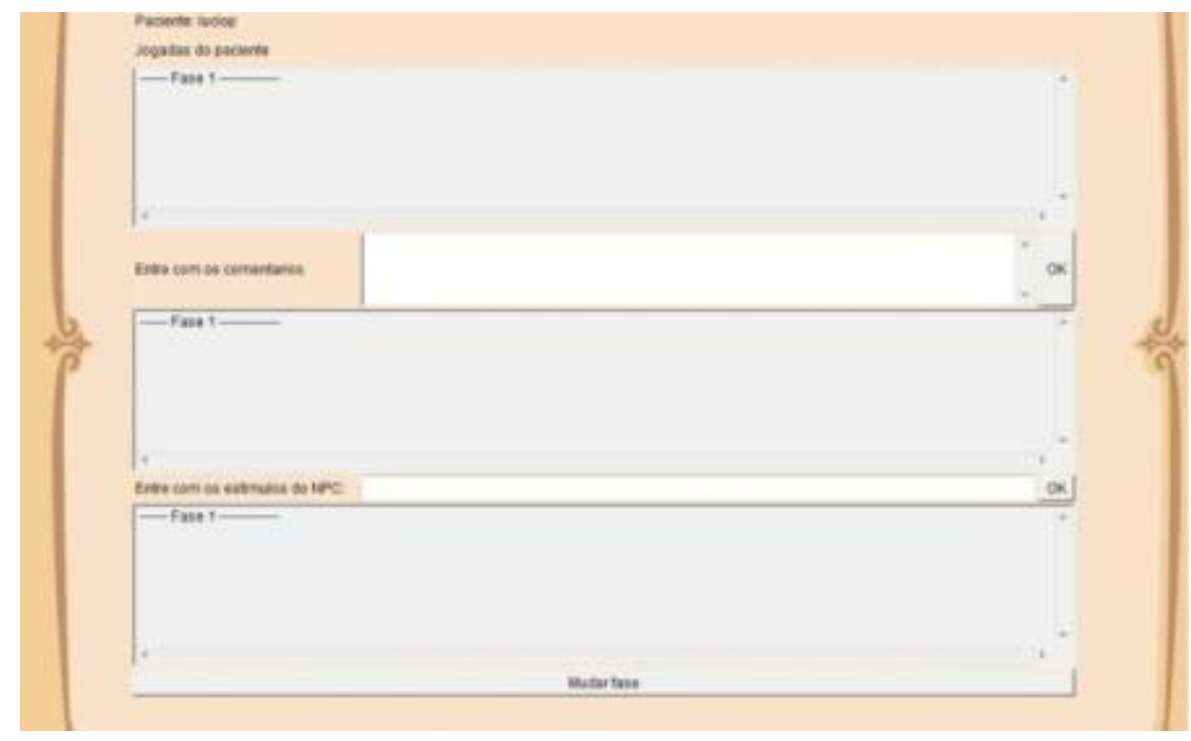

Figura 6. Interface do aplicador no jogo virtualizado

Caso seja necessário, o aplicador pode intervir na sessão de jogo da criança, por meio de mensagens de estímulo à elaboração de sua história. Para minimizar a interferência do aplicador, foi criado um recurso, denominado NPC - Non Playable Character, isto é, um personagem que não faz parte do jogo, mas que se apresenta no lugar do aplicador, exibindo as perguntas que ele necessita fazer à criança. No Cria Conto o NPC é representado por uma coruja e a mensagem textual é exibida dentro de um balão de diálogo. A coruja foi selecionada como porta-voz do aplicador porque se insere naturalmente no cenário do jogo, uma vez que é importante minimizar influências negativas das intervenções no processo de elaboração da história. Todas as mensagens enviadas pelo aplicador são também registradas em bases de dados, associadas à sessão de jogo da criança, para eventuais referências posteriores.

Atualmente, o jogo se encontra digitalizado até a versão 4. As fases a seguir, bem como o perfil diagnóstico, estão sendo desenvolvidas por teses de mestrado no NCE/UFRJ. Para jogar, é necessário primeiro cadastrar os pacientes (jogadores) e os aplicadores; acessar a seção Links e, em seguida, Jogos para começar a jogar.

Em termos técnicos, o Jogo Cria Conto foi desenvolvido a partir de uma plataforma tecnológica denominada Phidias, criada com intuito de abstrair complexidades da área de computação, fornecendo uma infraestrutura que promova ganhos de produtividade no desenvolvimento dos jogos. Na plataforma é possível capturar automaticamente eventos de interação da criança com os jogos e promover seu registro nas bases de dados. Além disso, fornece suporte para o desenvolvimento do ambiente visual do jogo, realizando o processamento gráfico dos elementos e implementando recursos de maneira a permitir a interação da criança de uma maneira mais natural com os elementos de cenário, como movimentação de peças e respostas sonoras.

O Phidias foi implementado em uma plataforma J2EE, unindo Applets e Servlets com tecnologias recentes, como Java Persistence API (JPA), responsável por gerenciar os acessos e as transações com o Banco de Dados. Todas as informações são armazenadas em um Banco de Dados relacional, tendo o MySQL como plataforma definida para armazenar os dados de todos os jogos gerados a partir do Phidias, incluindo o Cria Conto. Existem pesquisas sendo realizadas por mestrandos do NCE/UFRJ para a criação de um Data Mining para extrair os dados gerados pelos jogos e formar relatórios e diagnósticos.

A proposta é que para atender às crianças com deficiência visual ou que possuem visão subnormal (perda significativa da visão que não pode ser corrigida por tratamento clínico), outra interface gráfica seja implementada, mas garantindo que as funções cognitivas do jogo sejam preservadas. Todos os recursos que o jogo possui e que estão presentes na plataforma Phidias são mantidos, porém, ao invés de utilizar a interface gráfica usando Applets, uma interface gráfica em XHTML é utilizada. Os personagens e cenários do jogo seriam representados por gráficos vetoriais escaláveis $(\mathrm{SVG})$, que são criados por meio da linguagem XML e possuem formas bidimensionais. Cada gráfico inserido precisa estar relacionado a um som, que é iniciado quando o jogador passa o mouse sobre sua área. 


\section{Metalinguagem como canal de inclusão}

A metalinguagem caracteriza-se como uma linguagem ou forma própria de o aluno descrever outras linguagens-código ou sistemas de significação de acordo com seu mecanismo cognitivo. Esse processo, quando aplicado ao canal audiofonético, permite-nos perceber, por exemplo, pessoas com deficiência auditiva sendo instintivamente levadas a configurar um quadro de representações com estímulos sonoros variados, criando uma relação entre os demais sentidos presentes. Tal capacidade de abstração da representação gráfica apoiada nos demais sentidos é a principal viabilizadora da inclusão do deficiente visual no contexto social e, sobretudo, educacional. Desde o início, o processo comunicativo do deficiente visual é elaborado pela atribuição de significados configurados pela recursão e reflexão. Para eles a construção da representação mental do universo físico é um produto da elaboração dirigida na ótica de pessoas que possuem o sentido da visão.

Em termos metodológicos, a grande vantagem da elaboração dirigida e, por conseguinte, do Fio Condutor é que tanto seu processo metaprocessual quanto a avaliação-diagnóstica do perfil cognitivo da criança são produzidos por meio dos registros orais da criança, ou seja, do discurso dialógico, onde a captação do imaginário depende da verbalização da regra. Agindo ou interpretando, a criança conversa durante o tempo todo com o aplicador; logo, o ato de falar é pré-requisito para que o jogo possa ser aplicado na criança. Em caso de criança surda, o jogo pode ser aplicado desde que o aplicador também se comunique por meio da linguagem dos sinais.

Segundo Archambault e Olivier [8], a aplicação de acessibilidade a jogos é mais complexa do que acessibilidade a softwares em geral, pois existe o risco de que o jogo possa se descaracterizar. Estendida à questão pedagógica, há também um sério risco de empobrecimento das funções neurocognitivas do jogo, conduzindo a criança a uma resposta behaviorista ao invés de prover-lhe um espaço livre para a construção de significados. Diferentemente dos jogos de entretenimento, projetados para desenvolver totalmente autonomia ao cego, os jogos de avaliação cognitiva como o Cria Conto Virtual continuarão sendo mediados e seguindo tal qual a metodologia apresentada na seção 2 para as crianças que enxergam.

Archambault e Olivier recomendam ainda algumas questões no processo de desenvolvimento de jogos para deficientes visuais, que foram adaptados aos objetivos do Cria Conto Virtual sob a forma dos seguintes requisitos tecnológicos:

- Interface Gráfica: oferecer recurso de zoom, de ajustes de cores e de velocidade de navegação da tela da criança. As animações devem ser evitadas já que não poderão ser vistas. $\mathrm{O}$ pano de fundo que atualmente reveste a tela deve ser recortado, de forma que cada objeto do cenário possa ser tocado pelo mouse ou de comandos de teclado, emitindo o seu som correspondente;

- Áudio: uso de gravações originais e de outros recursos (narrações, diálogos, músicas, melodias, efeitos sonoros) que auxiliem a contextualização do jogo, uma vez que o aspecto visual não é considerado. O design metacognitivo será enriquecido com pistas para que a criança consiga identificar diferentes sons à medida que percorre as telas do jogo. Os eventos que não emitirem sons serão mais difíceis de serem correlacionados ao universo real; portanto, os sons devem se aproximar do universo infantil. $\mathrm{O}$ áudio pode ser utilizado também no sentido estético, como no caso de representar a percepção espacial através da variação do volume do som representando a profundidade do ambiente;

- Interação: não serão usadas mensagens explicativas ou descritivas. A criança receberá um retorno imediato, sonoro e suave ao iniciar o jogo, abandonar o jogo, caminhar com os personagens na tela, escolher ou devolver um personagem, atingir as extremidades da tela. O retorno imediato facilitará o reconhecimento do espaço a ser desenvolvido pela criança. Não haverá aplausos ou outros mecanismos que induzam a criança a selecionar e a posicionar seus personagens na tela. A sequência das seleções efetuadas será apresentada em intervalos de tempo mais espaçados e serão configuráveis para cada criança, uma vez que o tempo é fator importante no processo de aprendizagem do deficiente visual. A coruja continuará atuando como recurso para o aplicador;

- Usabilidade: o acesso da criança aos dispositivos do jogo (mouse, teclado, caixas de som, controles de cores e volumes, tela) será feita na tela da criança na parte superior, onde estarão descritos os principais atalhos de teclado, tais como ALT $+\mathrm{S}$, para subir na tela, ou ALT $+\mathrm{D}$, para descer na tela. Dessa forma, os comandos serão as primeiras informações disponíveis para a criança que usa leitor de tela;

Revista Brasileira de Computação Aplicada (ISSN 2176-6649), Passo Fundo, v.2, n. 1, p. 28-40, mar. 201036 
- Dispositivos: atualização do Phidias de forma que a plataforma ofereça recursos de tela, teclado, mouse, joystick, som 3D e sintetizador de voz.

\section{Considerações finais}

Método é um conjunto de normas que o sujeito deve colocar-se a
construir, testar, validar e corroborar o seu conhecimento.
Diferentemente da epistemologia, que busca definir a plataforma
do conhecimento a ser alcançado, o método busca indicar como
agir para alcançá-lo [5].

O jogo Cria Conto Virtual fundamenta-se em uma plataforma epistemológica e encontra-se em fase de aplicação experimental. A versão acessível está acontecendo simultaneamente. A pesquisa dos sons icônicos surgiu de uma necessidade real do jogo, que se preocupa em aproximar o jogo da memória auditiva do deficiente visual e, assim, atingir nosso objetivo, que é conhecer o seu imaginário. Temos como exemplo a resposta de um jovem que disse que reconhece o ponto de ônibus pelo som produzido pelas freadas do veículo. Assim, o jogo valoriza o canal audiofonético e resgata o imaginário coletivo.

\section{- Atividade de análise cognitiva da aprendizagem:}

- Etapa A1. Pesquisa dos sons icônicos que resgatam o imaginário coletivo dos deficientes visuais para alimentar o jogo. Pesquisa realizada com crianças e adolescentes deficientes visuais do IBC e AFAC;

- Etapa A2. Aplicação do Cria Conto Virtual e do Fio Condutor até a fase 3 em 30 crianças de 7 a 12 anos;

- Etapa A3. Validação dos crivos;

- Etapa A4. Aplicação do Cria Conto Virtual e do Fio Condutor até a fase 5 em 60 crianças de 7 a 12 anos, sendo 30 da escola pública e 30 crianças da escola privada;

- Etapa A5. Identificação do perfil cognitivo da criança a partir dos crivos;

- Etapa A6. Aplicação do Cria Conto Virtual e do Fio Condutor até a fase 5 em 30 crianças de 7 a 12 anos, deficientes visuais;

\section{- Atividades técnicas:}

- Etapa T1. Uso da Ferramenta pelos professores para análise da Tela do Aplicador;

- Etapa T2. Avaliação da usabilidade e acessibilidade do jogo às crianças de 7 a 12 anos;

- Etapa T3. Identificação de Novos Requisitos após a Etapa A2;

- Etapa T4: Ajustes na Ferramenta para a Etapa A3;

- Etapa T5. Ajustes na matematização dos crivos para a Etapa A6.

Existe uma equipe multidisciplinar composta por alunos mestrandos NCE/UFRJ com formação profissional em fonoaudiologia, psicologia, pedagogia, artes, letras, matemática e computação, os quais estão dedicados ao projeto de virtualização do jogo e na informatização dos crivos de avaliação cognitiva, fundamentadas por Seminério que sistematizou as dimensões de análise das histórias produzidas no imaginário por meio de dois eixos: o sintagmático e o paradigmático. O eixo paradigmático busca traçar as relações associativas entre a representação simbólica e seu conceito abstrato, materializados por meio da palavra. Para o Cria Conto foram mapeados os perfis egocêntrico, socializado e intermediário, explicitados na Figura 7. Já o eixo sintagmático busca identificar a forma como a criança formula associações entre signos. Para o Cria Conto foram identificados cincos aspectos relevantes, sistematizados na Figura 8:

- causalidade ou a capacidade da criança estabelecer relações de causa e efeito entre os acontecimentos, manifestada pelos nexos dos acontecimentos nas sentenças; 
- agentividade ou capacidade da criança de relacionar os personagens ao tema central da história, através de uma ação contínua integrada entre os agentes no decorrer da história;

- organização temporal ou capacidade da criança de identificar a existência ou não de uma ordem cronológica nas sentenças e como os fatos se organizam no tempo;

- contingência ou a capacidade da criança de abstração da criança e em quanto a história é capaz de ultrapassar os estímulos presentes. Considera o encadeamento de fatos observáveis e não observáveis;

- interação ou a capacidade da criança em integrar episódios e como ocorre a coesão desses fatos durante a história contada pela criança. São verificadas a coesão e a coerência entre as orações e parágrafos nas narrativas das crianças.

\begin{tabular}{|c|c|c|}
\hline E go & Intermediário & Socializa do \\
\hline $\begin{array}{l}\text {-Valores Éticos: } \\
\text { 1. moral pelo medo dos pais ou do } \\
\text { castigo; } \\
\text { 2. cisão (bom ou mau, baseado em } \\
\text { autoridade); } \\
\text { 3. lição de moral baseada em } \\
\text { arbitrariedade (no gosto egocêntrico); } \\
\text { 4. indiferença aos limites; } \\
\text { 5. recompensa pura e simples }\end{array}$ & $\begin{array}{l}\text { - Valores Éticos: } \\
\text { 1. moral pela dependência à } \\
\text { autoridade; } \\
\text { 2. possibilidade de dúvida } \\
\text { (sobre o que é bom, o que é } \\
\text { mau); } \\
\text { 3. lição de moral com } \\
\text { critério de autoridade } \\
\text { (conforme papai e mamãe } \\
\text { dizem) } \\
\text { 4. aceitação dos limites por } \\
\text { conveniência } \\
\text { 5. agir em função da } \\
\text { recompensa }\end{array}$ & $\begin{array}{l}\text { - Valores Éticos: } \\
\text { 1.moral pela compreensão e } \\
\text { incorporação das normas; } \\
\text { 2.possibilidade de integração } \\
\text { bem/mal, verdadeiro/ falso; } \\
\text { 3.lição de moral com critérios } \\
\text { éticos gerais (não está correto) } \\
\text { 4.internalização/questionamento } \\
\text { dos limites; } \\
\text { 5.recompensa em função do } \\
\text { respeito à norma }\end{array}$ \\
\hline $\begin{array}{l}\text { - Valor Religioso: contatos dialogados; } \\
\text { personificações familiares ("papai do } \\
\text { céu"); entes antropomorfizados (anjo } \\
\text { da guarda) }\end{array}$ & $\begin{array}{l}\text { - Valor Religioso: poderes } \\
\text { onipotentes, ilimitados (basta } \\
\text { rezar para que tudo se resolva) }\end{array}$ & $\begin{array}{l}\text { - Valor Religioso: considera que } \\
\text { "não basta rezar", deve-se agir } \\
\text { também (caridade, etc.) }\end{array}$ \\
\hline $\begin{array}{l}\text { - Verdade é o que a familia the dá (sem } \\
\text { confronto) }\end{array}$ & $\begin{array}{l}\text { - Verdade sob autoridade } \\
\text { familiar, defende o ponto de } \\
\text { vista dado por sua familia } \\
\end{array}$ & $\begin{array}{l}\text { - Verdade crítica (submete a } \\
\text { própria verdade à crítica) }\end{array}$ \\
\hline Preocl & $\begin{array}{l}\text { - Preocupação seletiva com o } \\
\text { outro (familia, amigos, etc.) }\end{array}$ & $\begin{array}{l}\text { - Preocupação generalizada com } 0 \\
\text { outro }\end{array}$ \\
\hline
\end{tabular}

Figura 7. Crivos do eixo paradigmático 


\begin{tabular}{|c|c|c|c|c|}
\hline 1) CAUSALDADF & 2) AGENIIVWADE & $\begin{array}{l}\text { 3) ORGANLZACÃO } \\
\text { TEMPORNL }\end{array}$ & 4) CONTINGÊNCIA & 5) INTEGRAÇÄO \\
\hline $\begin{array}{l}\text { - Ausência de nexos } \\
\text { causais explicitados } \\
\text { - Nexus forçados or } \\
\text { limitados } \\
\text { - -Texus intermitentes } \\
\text { - -Texus definidos }\end{array}$ & $\begin{array}{l}\text { - Alsência de agentividade } \\
\text { - Açopes mínimas elou } \\
\text { fragmentárias } \\
\text { - Agentes parcialmente } \\
\text { inte grados } \\
\text { - Ação contifua, ntegrada e } \\
\text { multifocal }\end{array}$ & $\begin{array}{l}\text { - Temporalidade rula elou } \\
\text { absurda } \\
\text { - Momentos isolados } \\
\text { - Sequência não } \\
\text { organizada } \\
\text { - Sequência organizada }\end{array}$ & $\begin{array}{l}\text { - Jã insery âo da prancla } \\
\text { ou Descrição di } \\
\text { otservável } \\
\text { - Finação no obscrvavcl } \\
\text { - Introdução do fatos } \\
\text { nowos } \\
\text { - Encadeamente de tatos } \\
\text { otscrvávcis c năo } \\
\text { otserváve1s }\end{array}$ & $\begin{array}{l}\text { - Quadros isolados } \\
\text { - Conexões parciais } \\
\text { - Flumo lacunar } \\
\text { - Fluxo rontínilo }\end{array}$ \\
\hline
\end{tabular}

Figura 8. Crivos do eixo sintagmático

A avaliação destina-se a três agentes importantes no processo de criação e implementação do sistema: a usabilidade do software, a ergonomia e a proposta cognitiva do jogo Cria Conto. Foram produzidos três questionários: da criança, que avalia o grau de satisfação que a criança sentiu jogando; do aplicador, para detectar seu entendimento do jogo quanto ao processo de intervenção, acompanhamento e avaliação das respostas da criança; do neurocientista, que aborda questões técnicas de captura de informações, eficiência da avaliação da criança feita com base nos crivos e pontos do sistema que podem ser aperfeiçoados e acrescentados em versões futuras do software.

O jogo metacognitivo Cria Conto no concreto é de uso restrito e de difícil reprodução em larga escala. A sua virtualização facilitará a democratização e também garantirá ao especialista ou professor um recurso de avaliação mais seguro e rápido. Se fosse aplicado manualmente, despenderia muito tempo e correria o risco de uma margem de erro mais elevada. Podemos dizer que esta é a grande diferença entre os jogos didáticos e os jogos metacognitivos, já que os últimos permitem que a criança dê um salto metaprocessual e que o professor acompanhe seu aluno com um forte alicerce teórico.

A matematização dos crivos do jogo facilita não somente a avaliação do perfil cognitivo imaginário da criança como o aparecimento de padrões, que ajudarão o professor a identificar possíveis inferências para ajudálas em seu planejamento de aula.

O que se pretende afirmar é que o nosso ato de pensar é sempre um ato imaginário, não a captação supostamente passiva de organização de pensamento ou de alguma realidade [3]. Nesse sentido, a iniciativa pioneira oferecida pelo Cria Conto Virtual fornece aporte substancial no desenvolvimento infantil de construção do conhecimento.

\section{Referências}

[1] IBGE. 2009. Instituto Brasileiro de Geografia e Estatística. Página da Internet. Disponível em: $<$ http://www.ibge.gov.br>. Acesso em: 05 jul. 2009.

[2] MARQUES, C. V. M. 2009. Laboratório de neuropsicologia cognitiva-projeto geral: avaliação de crianças deficientes visuais. Rio de Janeiro: NCE/UFRJ, 10 p. (Relatório Técnico, 2/9).

[3] SEMINÉRIO, F. L. P.; ANSÈLME, C. R.; CHAHON, M. 1998. Imaginário cognitivo: uma fronteira entre consciência e inconsciente. Rio de Janeiro: Arquivos Brasileiros de Psicologia, v. 49, p. 94-107.

[4] SEMINÉRIO, F. L. P. 1985. O problema do método: limite ou expansão em ciências humanas. Rio de Janeiro: Arquivos Brasileiros de Psicologia, v. 1, p. 1-8 
[5] SEMINÉRIO, F. L. P. 1985. Infra-estrutura da cognição (II): linguagens e canais morfogenéticos. p. 36-37, Rio de Janeiro, FGV.

[6] SEMINÉRIO, F. L. P. 1997. Novos rumos na psicologia e na pedagogia: metacognição - uma nova opção. Arquivos Brasileiros de Psicologia, Rio de Janeiro, v. 49, n. 3, p. 5-22, jul./set.

[7] MARQUES, C. V. et al. 2008. Cria Conto: uma proposta de avaliação do perfil cognitivo de crianças a partir da análise do imaginário. Relatório Técnico de Neuropedagogia e Informática. NCE/IM - Universidade Federal do Rio de Janeiro.

[8] ARCHAMBAULT, D.; OLIVIER, D. 2005. How to make games for visually impaired children. In Proceedings of the 2005 ACM SIGCHI international Conference on Advances in Computer Entertainment Technology (Valencia, Spain, June 15-17, 2005). ACE '05, vol. 265. ACM, New York, NY, 450-453. 